\title{
The clinical impact and cost implications of endoscopic ultrasound on the use of endoscopic retrograde cholangiopancreatography in a Canadian university hospital
}

\author{
Nassir Alhayaf MD FRCPC, Eoin Lalor MBBCh FRCPC, Vincent Bain MD FRCPC, \\ John McKaigney MD FRCPC, Gurpal Singh Sandha MBBS FRCPC
}

\begin{abstract}
N Alhayaf, E Lalor, V Bain, J McKaigney, GS Sandha. The clinical impact and cost implications of endoscopic ultrasound on the use of endoscopic retrograde cholangiopancreatography in a Canadian university hospital. Can J Gastroenterol 2008;22(2):138-142.
\end{abstract}

BACKGROUND: Endoscopic ultrasound (EUS) is a safe alternative to endoscopic retrograde cholangiopancreatography (ERCP) for diagnostic biliary imaging in choledocholithiasis. Evidence linking a decline in diagnostic ERCP with the introduction of EUS in clinical practice is limited.

OBJECTIVE: To assess the clinical impact and cost implications of a new EUS program on diagnostic ERCP at a tertiary referral centre. PATIENTS AND METHODS: A retrospective review was performed of data collected during the first year of EUS at the University of Alberta Hospital (Edmonton, Alberta). Patients were referred for ERCP because of suspicion of choledocholithiasis based on clinical, biochemical and/or radiological parameters. If they were assessed to have an intermediate probability of choledocholithiasis, EUS was performed first. ERCP was performed if EUS suggested choledocholithiasis, whereas patients were clinically followed for six months if their EUS was normal. Cost data were assessed from a third-party payer perspective, and cost savings were expressed in terms of ERCP procedures avoided.

RESULTS: Over 12 months, 90 patients (63 female, mean age 58 years) underwent EUS for suspected biliary tract abnormalities. EUS suggested choledocholithiasis in 20 patients (22\%), and this was confirmed by ERCP in 17 of the 20 patients. EUS was normal in 69 patients, and none underwent a subsequent ERCP during a six-month follow-up period. One patient had pancreatic cancer and did not undergo ERCP. The sensitivity and specificity of EUS for choledocholithiasis were $100 \%$ and $96 \%$, respectively. A total of 440 ERCP procedures were performed over the same 12-month period, suggesting that EUS resulted in a $14 \%$ reduction in ERCP procedures (70 of 510). There were no complications of EUS. The cost of 90 EUS procedures was $\$ 42,840$, compared with $\$ 108,854$ for 70 ERCP procedures. The cost savings for the first year were $\$ 66,014$. CONCLUSION: EUS appears to be accurate, safe and cost effective in diagnostic biliary imaging for suspected choledocholithiasis. The impact of EUS is the avoidance of ERCP in selected cases, thereby preventing the risk of complications. Diagnostic ERCP should not be performed in centres and regions with physicians trained in EUS.

Key Words: Cost analysis; Endoscopic retrograde cholangiopancreatography; Endosonography
Les conséquences en clinique et sur les coûts de l'échoendoscopie sur l'utilisation de la cholangiopancréatographie rétrograde endoscopique dans un hôpital universitaire canadien

HISTORIQUE : L'échoendoscopie (ÉE) est une solution de rechange sécuritaire à la cholangiopancréatographie rétrograde endoscopique (CPRE) pour l'imagerie biliaire diagnostique de la lithiase cholédocienne. Les données reliant une diminution des CPRE diagnostiques à l'arrivée de l'ÉE en pratique clinique sont limitées.

OBJECTIF : Évaluer les conséquences en clinique et sur les coûts d'un nouveau programme d'ÉE sur la CPRE diagnostique dans un centre d'aiguillage tertiaire.

PATIENTS ET MÉTHODOLOGIE : Les auteurs ont procédé à une analyse rétrospective des données recueillies pendant la première année de l'ÉE au University of Alberta Hospital (Edmonton, Alberta). Les patients étaient aiguillés vers une CPRE en raison d'une lithiase cholédocienne présumée d'après des paramètres cliniques, biochimiques ou radiologiques. Si on évaluait qu'ils présentaient une probabilité intermédiaire de lithiase cholédocienne, on procédait d'abord à l'ÉE. On procédait à la CPRE si l'ÉE laissait supposer une lithiase cholédocienne, et les patients étaient suivis en clinique pendant six mois si leur ÉE était normale. Les auteurs ont évalué les données de coût selon une perspective de tiers payeur et ont exprimé les économies selon le nombre de CPRE évitées.

RÉSULTATS : Sur une période de 12 mois, 90 patients ( 63 femmes, âge moyen de 58 ans) ont subi une ÉE en raison d'une présomption d'anomalies du tractus biliaire. L'ÉE a laissé supposer une lithiase cholédocienne chez 20 patients (22\%), confirmée par une CPRE chez 17 d'entre eux. L'ÉE était normale chez 69 patients, et aucun n'a subi d'autre CPRE pendant la période de suivi de six mois. Un patient était atteint de cancer pancréatique et n'a pas subi de CPRE. La sensibilité et la spécificité de l'ÉE pour la lithiase cholédocienne s'établissaient à $100 \%$ et à $96 \%$, respectivement. Au total, $440 \mathrm{CPRE}$ ont été effectuées pendant la même période de 12 mois, ce qui indique une réduction des CPRE de $14 \%$ (70 sur 150) imputable à l'ÉE. L'ÉE n'a suscité aucune complication. Les 90 ÉE ont coûté 42840 \$, par rapport à 108854 \$ pour les 70 CPRE. Les économies pour la première année s’élevaient à $66044 \$$.

CONCLUSION : L'ÉE semble précise, sécuritaire et rentable pour l'imagerie biliaire diagnostique de la lithiase cholédoque présumée. L'ÉE a comme répercussion d'éviter la CPRE dans certains cas, ce qui prévient le risque de complications. Il ne faut pas procéder à des CPRE diagnostiques dans les centres et les régions où travaillent des médecins formés pour effectuer des ÉE.

Division of Gastroenterology, Department of Internal Medicine, University of Alberta Hospital, Edmonton, Alberta

Correspondence: Dr Gurpal Singh Sandha, Division of Gastroenterology, University of Alberta, Zeidler Ledcor Centre, 130 University Campus,

Edmonton, Alberta T6G 2X8. Telephone 780-492-8170, fax 780-492-1699, e-mail gurpal.sandha@ualberta.ca

Received for publication July 17, 2007. Accepted September 6, 2007 
E ndoscopic retrograde cholangiopancreatography (ERCP) remains the gold standard for pancreaticobiliary evaluation. There is, however, a risk of complications associated with ERCP, including pancreatitis (5.4\%) (1). The benefit of ERCP outweighs the risk if a therapeutic intervention such as biliary sphincterotomy with stone extraction is necessary. However, the availability of safer, yet equally accurate, alternatives for diagnostic biliary imaging in the assessment of suspected choledocholithiasis can eliminate the risk of post-ERCP pancreatitis associated with diagnostic ERCP. Endoscopic ultrasound (EUS) is one such procedure that has been proven to be as accurate for detecting choledocholithiasis as ERCP (2-12). Until recently, EUS was only available in a few tertiary centres in Canada. Because more physicians have acquired training and more resources have been allocated to the purchase of this new technology, most of the tertiary centres across Canada are now equipped with EUS (13).

The cost benefit of EUS as an initial modality for biliary imaging has also been assessed in economic analyses, including one Canadian study $(14,15)$. These suggest that EUS is the preferred strategy for diagnostic imaging of the biliary tract before laparoscopic cholecystectomy (LC) to exclude choledocholithiasis or, in acute biliary pancreatitis, to allow therapeutic ERCP and stone extraction if indicated. The benefit depends on relative costs of EUS and ERCP, as well as availability and expertise in EUS.

There have been reports of a decrease in the use of diagnostic ERCP as a result of the introduction of EUS in clinical practice $(16,17)$. Meenan et al $(17)$ reported that the proportion of diagnostic ERCP relative to therapeutic ERCP decreased from $33 \%$ the year before to $14 \%$ the year after the introduction of EUS.

The objective of our study was to evaluate both the clinical impact and the cost implication of a new EUS program on the frequency of performing diagnostic ERCP at a Canadian tertiary referral centre over the first 12 months.

\section{Patients studied}

\section{PATIENTS AND METHODS}

A retrospective study was performed involving patients who were referred to the Division of Gastroenterology at the University of Alberta Hospital (UAH) in Edmonton, Alberta, for ERCP because of suspected choledocholithiasis based on clinical symptoms (ie, biliary colic, defined as right upper quadrant pain with or without radiation to the right scapular area and/or nausea) with or without biochemical abnormality (ie, elevated liver enzymes) and/or ultrasonographic evidence of biliary abnormality (common bile duct [CBD] stone and/or dilation). Patients went directly to ERCP if radiological studies suggested the presence of a stone in the CBD. Patients with intermediate probability of requiring sphincterotomy (discussed below) underwent EUS instead, as an initial investigation for biliary imaging, as suggested by recently published guidelines (18). The experience of physicians during the first 12 months of initiating EUS as a new program at the UAH is reported.

\section{EUS examination}

EUS was instituted as a new clinical program in February 2004. The UAH is the only centre providing EUS for northern Alberta, and is the referral centre for parts of the adjacent provinces of British Columbia and Saskatchewan, servicing a total population of approximately 1.8 million people. All procedures were performed by a single operator (GSS) who was trained in both diagnostic radial and interventional linear EUS (more than 350 procedures in training). All procedures were performed using a Pentax EG 3630UR radial echoendoscope (Pentax Precision Instruments, USA) in the endoscopy unit under conscious sedation using midazolam and meperidine. The CBD was considered to have been completely visualized endosonographically when viewed both from the duodenal cap (proximal CBD and mid-CBD) and from the second part of the duodenum in front of the ampulla of Vater (distal CBD). A stone in the CBD was defined as a definite hyperechoic object within the lumen of the duct casting an acoustic shadow.

\section{Clinical evaluation}

Patients were referred for ERCP from the community, other referring hospitals and from the inpatient consult service at the UAH. The decision to perform EUS as the initial procedure instead of ERCP was made by a consultant gastroenterologist after discussion with the endosonographer. This was a clinical judgment for which the criteria were resolution of abdominal pain and improvement in, or resolution of, the initial biochemical liver enzyme abnormality. These criteria suggested possible passage of a presumed CBD stone; hence, a less invasive means of biliary imaging instead of an ERCP was a consideration. If the EUS suggested a stone in the CBD, ERCP was performed the same day or within $72 \mathrm{~h}$. ERCP was performed by one of four biliary endoscopists (EL, VB, JM or GSS). All ERCP procedures were performed using the Olympus TJF160F side-viewing duodenoscope (Olympus America Corp, USA). If a CBD stone was confirmed, biliary sphincterotomy was performed, followed by basket or balloon catheter extraction.

If the EUS examination reported a normal CBD with no stones, patients were sent back to the care of the referring physician. Because all patient information within Edmonton's Capital Health Region is accessible on a computerized database, it was possible to retrieve information relating to any subsequent ERCP that a patient may have had within six months in any hospital within the region. To assess the proportion of ERCP procedures that were diagnostic, the overall number of ERCP procedures performed at the UAH during the same 12 -month period was used as the denominator.

\section{Cost analysis}

Cost data were assessed from a third-party payer perspective (Alberta Health and Wellness reimbursements for cost of procedures, hospitalization and physician fees), and the cost benefit assessment was performed by comparing the costs (all values expressed in Canadian dollars) of EUS and ERCP based on a modification of previously published Alberta Health and Wellness reimbursement data (Table 1) (14). The cost efficacy was expressed in terms of ERCP procedures avoided minus the cost of EUS. The cost of diagnostic ERCP also included the cost of hospitalization resulting from a $5.4 \%$ risk of post-ERCP pancreatitis (1). It was estimated that mild or moderate post-ERCP pancreatitis would result in a mean hospitalization period of three days. The cost of severe pancreatitis requiring intensive care was not factored into the cost analysis, because this occurs in less than $1 \%$ of patients with post-ERCP pancreatitis. Also, indirect costs due to loss of productivity resulting from patient hospitalization were not estimated in the present cost analysis. 


\section{TABLE 1 \\ Procedure cost components for diagnostic endoscopic retrograde cholangiopancreatography (ERCP), endoscopic ultrasound (EUS) and the University of Alberta Hospital* (UAH) general ward based on tabulation of local salaries, equipment costs, service contracts, hospital overhead and physician reimbursement}

\begin{tabular}{|c|c|}
\hline Descriptions of cost component & Cost (\$) \\
\hline \multicolumn{2}{|l|}{ Diagnostic ERCP } \\
\hline \multicolumn{2}{|l|}{ Diagnostic imaging component } \\
\hline Radiology technician time and benefits, and clerical costs & 61.50 \\
\hline Radiographic film and contrast & 13.80 \\
\hline Fluoroscopy equipment service package (per case component) & 14.00 \\
\hline Radiologist reimbursement $^{\dagger}$ & 67.34 \\
\hline \multicolumn{2}{|l|}{ Gastroenterology component } \\
\hline $\begin{array}{l}\text { Nursing salary and benefits (two nurses for the procedure), } \\
\text { including recovery room }\end{array}$ & 171.29 \\
\hline Medications & 6.36 \\
\hline $\begin{array}{l}\text { Medical and surgical supplies (including papillotome, } \\
\text { guidewire, gloves, intravenous, oxygen tubing, etc), } \\
\text { scope disinfecton and laundry }\end{array}$ & 524.49 \\
\hline $\begin{array}{l}\text { Scope and equipment wear per case (based on annual repairs } \\
\text { for } 2002 \text { [900 cases] and } 5000 \mathrm{~h} \text { per videoprocessor life) }\end{array}$ & 32.22 \\
\hline Overhead costs (per case) & 88.64 \\
\hline Gastroenterologist endoscopist reimbursement for ERCP ${ }^{\dagger}$ & 231.26 \\
\hline Total & $1,210.97$ \\
\hline \multicolumn{2}{|l|}{ Diagnostic EUS } \\
\hline $\begin{array}{l}\text { Nursing salary and benefits (one nurse for the procedure), } \\
\text { including recovery room }\end{array}$ & 123.33 \\
\hline Medications & 2.57 \\
\hline $\begin{array}{l}\text { Medical and surgical supplies (including echoendoscope balloon), } \\
\text { scope disinfection and laundry }\end{array}$ & ), 38.82 \\
\hline $\begin{array}{l}\text { Scope and equipment wear per case (based on } 2000 \text { uses } \\
\text { per scope life, } 5000 \mathrm{~h} \text { per US processor life and } 5000 \mathrm{~h} \\
\text { per video processor life) }\end{array}$ & 84.16 \\
\hline Overhead costs (per case) & 88.64 \\
\hline Gastroenterologist reimbursement for EUS ${ }^{\dagger}$ & 138.40 \\
\hline Total & 475.92 \\
\hline \multicolumn{2}{|l|}{ UAH inpatient charges } \\
\hline $\begin{array}{l}\text { General ward per diem, including supplies (intravenous fluids), } 2, \\
\text { medications (analgesics) and overhead allocation }\end{array}$ & $2,007.00$ \\
\hline Total & $2,007.00$ \\
\hline
\end{tabular}

*Located in Edmonton, Alberta; ${ }^{\dagger}$ Based on Alberta health care physician reimbursements (April 2006). Adapted from reference 14

Ethics

The protocol was approved by the Health Research Ethics Board of the UAH, including approval for conducting the review of patient data for the present study.

\section{Statistical analysis}

Descriptive statistics were used to describe differences between various parameters. Sensitivity and specificity analyses were performed using standard $2 \times 2$ tables.

\section{RESULTS}

In the first 12 months after starting the EUS program at the UAH in February 2004, a total of 329 patients underwent EUS for various indications. Of these patients, 90 (27\%) were originally referred for ERCP because of a suspicion of
TABLE 2

Clinical characteristics of patients who underwent endoscopic ultrasound

\begin{tabular}{lc}
\hline Characteristic & Patients \\
\hline Total patients, $\mathrm{n}$ & 90 \\
Female, $\mathrm{n}(\%)$ & $63(70)$ \\
Age, years, mean (range) & $58(17-90)$ \\
Presenting clinical features, $\mathrm{n}(\%)$ & \\
Biliary colic plus abnormal liver enzymes & $28(31)$ \\
Abnormal liver enzymes only & $14(16)$ \\
Biliary colic plus abnormal liver enzymes plus dilated CBD & $12(13)$ \\
Dilated CBD plus abnormal liver enzymes & $11(12)$ \\
Biliary colic plus dilated CBD & $10(11)$ \\
Biliary colic only & $8(9)$ \\
Dilated CBD only & $7(8)$ \\
\hline
\end{tabular}

CBD Common bile duct

choledocholithiasis but instead underwent EUS for imaging of the biliary tree. Patients presented with or were referred for clinical symptoms of abdominal pain suggestive of biliary colic with or without elevated liver enzymes and/or unexplained biliary dilation seen on abdominal ultrasound. There were 63 female patients $(70 \%)$, and the mean age of the entire group was 58 years (range 17 to 90 years). Table 2 describes the demographic data of this group.

\section{Clinical efficacy of EUS}

EUS was performed within $24 \mathrm{~h}$ of the original referral and suggested the presence of choledocholithiasis in 20 of 90 patients, all of whom subsequently underwent ERCP with therapeutic intent. Of those 20 patients, 17 patients had choledocholithiasis confirmed on ERCP with successful extraction of the stone(s) after biliary sphincterotomy. ERCP revealed a normal cholangiogram in three patients, and a sphincterotomy was not performed. All three of the presumed false-positive results (which also may have resulted from spontaneous passage of the stone) were within the first 12 weeks of initiating EUS (ie, they could have been the result of an operator learning curve). Of the 20 patients undergoing ERCP, 17 patients had abnormal liver enzymes and three patients had normal liver enzymes. Of the latter three patients, two were found to have stones in their CBD on ERCP. Both of these patients had symptoms of nausea, and an abdominal ultrasound revealed dilated bile ducts.

One patient was found to have a mass in the pancreatic body and underwent EUS-guided fine-needle aspiration biopsy. Cytology revealed pancreatic adenocarcinoma. ERCP was not performed in this patient.

EUS did not identify any CBD abnormality in 69 patients, and thus, an ERCP was not performed. None of these patients underwent ERCP in the six-month follow-up period.

These results indicate a sensitivity, specificity, positive predictive value and negative predictive value of $100 \%, 96 \%$, $85 \%$ and $100 \%$, respectively, for EUS in identifying choledocholithiasis (Table 3).

There were no complications of EUS.

\section{Clinical impact of EUS on ERCP}

During the same 12 months, a review of the endoscopy unit data revealed that 440 ERCP procedures were performed at the 
UAH. If EUS had not been available, it is assumed that as many as 70 additional ERCP procedures would have been performed, accounting for a total of 510 procedures. This indicates that there was a $14 \%(70 / 510)$ reduction in diagnostic ERCP procedures at the UAH during the first year of implementing EUS as a new program.

\section{Cost implications of EUS}

The current estimated cost of an EUS procedure in Alberta was $\$ 476$. The total cost of 90 EUS procedures was $\$ 42,840$. In comparison, the cost of a diagnostic ERCP was $\$ 1,211$. The total cost saved by avoiding 70 additional ERCP procedures includes the cost of 70 ERCP procedures plus the cost of hospitalization resulting from a $5.4 \%$ risk of pancreatitis (four patients). The average in-hospital stay on a general medical ward for mild-to-moderate post-ERCP pancreatitis was estimated to be three days. The total cost amounted to $\$ 108,854(70 \times \$ 1,211+\$ 2,007$ per day $\times$ three days $\times$ four patients). The total cost of ERCP per patient was therefore calculated to be $\$ 1,555$. The total cost savings for the UAH by adopting this approach of EUS (where indicated) before ERCP for the study year was $\$ 66,014$.

\section{DISCUSSION}

EUS in Canada, unlike the United States, has seen slow acceptance as a diagnostic clinical tool. Recently, most of the major centres across the country have invested in this technology, which is perceived as expensive and of uncertain cost effectiveness (13). This has been a result of data supporting the use of EUS as a diagnostic tool of choice for many gastrointestinal-related indications, as well as increasing interest and training among endoscopists. Prospective studies and cost analyses have proven EUS to be more cost effective than ERCP for initial biliary imaging $(19,20)$. However, to date, no data assessing the real-life clinical and cost impacts of EUS as a new program on the use of ERCP procedures have been published.

In our centre (UAH), ERCP is no longer performed if EUS reports a normal bile duct without evidence of choledocholithiasis. All patient-related activity is captured on a computerized database within the Edmonton Capital Health Region, so we were able to capture patient data to document whether subsequent ERCP was performed. A follow-up of this database at six months did not reveal any ERCPs required for the EUS-negative patients. Because ERCP is only provided in Edmonton, we are confident that any persistence or recurrence of symptoms or liver enzyme abnormalities would have prompted a re-referral and subsequent procedure (EUS or ERCP) within the region, and would have been captured on the regional database. There is a small possibility that some patient visits for recurrent biliary colic may have been missed, but we believe this is unlikely, although this is a limitation of the retrospective design of our study.

Our results confirm EUS to be an accurate and safe alternative to ERCP for diagnostic biliary imaging in suspected choledocholithiasis. All EUS procedures were performed by a single operator. Diagnostic accuracy is dependent on operator expertise. The three 'false-positive' cases in our study occurred within the first three months and may represent a learning curve. On the other hand, it is conceivable that spontaneous passage of the stone(s) from the CBD may have occurred between the EUS and ERCP examinations. More importantly, none of the
TABLE 3

Clinical efficacy of endoscopic ultrasound (EUS) for choledocholithiasis compared with endoscopic retrograde cholangiopancreatography (ERCP)

\begin{tabular}{lcrrr}
\hline & & \multicolumn{2}{c}{ ERCP, $\mathbf{n}$} & \\
\cline { 3 - 4 } & & + & - & Total \\
\hline EUS, $\mathrm{n}$ & + & 17 & 3 & 20 \\
& - & 0 & 70 & 70 \\
& Total & 17 & 73 & 90 \\
\hline
\end{tabular}

EUS had a sensitivity, specificity, positive predictive value and negative predictive value of $100 \%, 96 \%, 85 \%$ and $100 \%$, respectively. An ERCP that was not performed within a six-month follow-up period was taken as a surrogate marker for a negative ERCP. - Negative; + Positive

EUS-negative cases required ERCP during the six-month follow-up period of the present study.

Recently, the National Institutes of Health State-of-theScience Conference Statement (21) made recommendations that ERCP be strongly considered a therapeutic procedure, because newer and safer modalities for diagnostic biliary imaging have emerged. These modalities include EUS, magnetic resonance cholangiopancreatography (MRCP) and intraoperative cholangiography (IOC) during a laparoscopic cholecystectomy (LC). Hilsden et al (22) assessed the possible effect of these alternative modalities for biliary imaging on the patterns of ERCP practice in a Canadian province (Alberta). Between 1994 and 2001, the total number of ERCP procedures performed remained stable, but the proportion of therapeutic ERCPs increased from $33 \%$ to $70 \%$; however, no data were presented linking this trend to the increase in EUS in Alberta.

Within the first year of our EUS program, we avoided 70 diagnostic ERCP procedures. With increasing awareness of the availability of EUS, the number of diagnostic ERCP procedures may decline even further. Factoring in the cost of hospitalization for post-ERCP pancreatitis, the estimated cost saving (for one year) for our hospital alone was $\$ 66,014$. If our results are extrapolated to the entire Edmonton Capital Health region, where approximately 1500 ERCP procedures are performed annually, the introduction of EUS could potentially reduce this number by 210 ERCP procedures. The total annual cost savings would be $\$ 198,042$ for the entire region. These data indicate that the capital costs invested for the purchase of EUS equipment could be recovered within a period of 2.5 years simply by reducing the number of unnecessary diagnostic ERCP procedures. There are further cost implications of EUS, especially related to the diagnosis and staging of gastrointestinal and nongastrointestinal malignancy, suggesting that this cost benefit could be appreciated much earlier. However, this discussion is beyond the scope of the present paper.

The degree of cost benefit is dependent on the procedural reimbursement rates. In Alberta, the reimbursement for EUS is significantly less than comparative reimbursements in the United States. Scheiman et al (19) prospectively compared the clinical efficacies of EUS and MRCP when performed within $24 \mathrm{~h}$ before ERCP in patients with biliary disease. As far as choledocholithiasis was concerned, EUS was more sensitive than MRCP (80\% compared with 40\%), although the specificities of both modalities were the same. The costs of each strategy per patient were assessed to be US\$1,111 for EUS, US $\$ 1,145$ for MRCP and US $\$ 1,346$ for ERCP. The cost difference was not significant, although initial EUS was the most 
cost effective by avoiding unnecessary ERCP. In comparison, our study assessed the cost per patient to be $\$ 476$ for EUS and $\$ 1,555$ for ERCP. This is a highly significant cost difference. However, even if the reimbursement for EUS increases in our health care system, it is unlikely that EUS as an initial strategy would be more expensive than performing ERCP in all patients. Even though MRCP is an alternate noninvasive method to image the biliary tree, we did not include MRCP in our cost comparison. In our centre, the timing and availability of MRCP precludes its acceptability as an investigation to determine the need for prompt ERCP, whereas EUS is more readily accessible. Certainly, either EUS or MRCP can be chosen based on local availability $(19,16)$. We did not include IOC during LC in our comparative cost analysis. In Alberta, IOC costs approximately $\$ 55$. This certainly appears to be a less expensive strategy than EUS, but in clinical practice, our general surgeons often request clearance of the CBD before surgery. In patients with an intermediate probability of a CBD stone, EUS can provide that information before LC.

\section{CONCLUSIONS}

EUS is an accurate, safe and cost-effective investigation for biliary imaging when choledocholithiasis is suspected clinically. The real clinical impact of EUS is in such patients with suspected choledocholithiasis, in whom a low likelihood of therapeutic intervention precludes the need for an invasive, diagnostic ERCP, thereby preventing the possibility of potential complications. Diagnostic ERCP should not be performed if the likelihood of a therapeutic intervention is low, especially if there is access to a centre that is equipped with EUS and a physician trained in accurate endosonographic interpretation. Outside major tertiary centres, noninvasive measures for diagnostic biliary imaging should preferably be sought as the initial method of investigation (ie, referral for EUS, MRCP or even IOC, depending on local availability).

ACKNOWLEDGEMENTS: The authors thank Dr Sander van Zanten for his critical review of the manuscript of the present paper.

The abstract of the present article was presented as a poster at the Annual Meeting of the Canadian Association of Gastroenterology (Canadian Digestive Diseases Week), February 16 to 20, 2007, Banff, Alberta, and published in Can J Gastroenterol 2007; 21(Suppl A):149A. (Abst)

CONFLICT OF INTEREST: None of the authors have any conflict of interest to disclose.

\section{REFERENCES}

1. Freeman ML, Nelson DB, Sherman S, et al. Complications of endoscopic biliary sphincterotomy. N Engl J Med 1996;335:909-18.

2. Denis BJ, Bas V, Goudot C, et al. Accuracy of endoscopic ultrasonography for diagnosis of common bile duct stones. Gastroenterology 1993;104:A358. (Abst)

3. Amouyal P, Amouyal G, Levy P, et al. Diagnosis of choledocholithiasis by endoscopic ultrasonography. Gastroenterology 1994;106:1062-7.

4. Napoleon B, Pujol B, Ponchon T, Keriven O, Souquet JC. Prospective study of the accuracy of echo-endoscopy for the diagnosis of bile duct stones. Endoscopy 1994;26:442.

5. Salmeron M, Simon JF, Houart R, Lémann M, Johannet H. Endoscopic ultrasonography versus invasive methods for the diagnosis of common bile duct stones. Gastroenterology 1994;106:A357. (Abst)

6. Shim CS, Joo JH, Park CW, et al. Effectiveness of endoscopic ultrasonography in the diagnosis of choledocholithiasis prior to laparoscopic cholecystectomy. Endoscopy 1995;27:428-32.

7. Palazzo L, Girollet PP, Salmeron M, et al. Value of endoscopic ultrasonography in the diagnosis of common bile duct stones: Comparison with surgical exploration and ERCP. Gastrointest Endosc 1995;42:225-31.

8. Prat F, Amouyal G, Amouyal P, et al. Prospective controlled study of endoscopic ultrasonography and endoscopic retrograde cholangiography in patients with suspected common-bileduct lithiasis. Lancet 1996;347:75-9.

9. Sugiyama M, Atomi Y. Endoscopic ultrasonography for diagnosing choledocholithiasis: A prospective comparative study with ultrasonography and computed tomography. Gastrointest Endosc 1997;45:143-6.

10. Norton SA, Alderson D. Prospective comparison of endoscopic ultrasonography and endoscopic retrograde cholangiopancreatography in the detection of bile duct stones. Br J Surg 1997;84:1366-9.

11. Canto MI, Chak A, Stellato T, Sivak MV Jr. Endoscopic ultrasonography versus cholangiography for the diagnosis of choledocholithiasis. Gastrointest Endosc 1998;47:439-48.

12. Buscarini E, Tansini P, Rossi S, et al. Endoscopic ultrasonography for suspected choledocholithiasis: Outcome analysis in 150 patients. Digestion 1998;59:A199. (Abst)
13. Burtin P, Nash C, Depew W, et al. EUS in Canada in 2004. Acta Endoscopica 2005;35:49-52.

14. Romagnuolo J, Currie G, for the Calgary Advanced Therapeutic Endoscopy Center study group. Noninvasive vs. selective invasive biliary imaging for acute biliary pancreatitis: An economic evaluation by using decision tree analysis. Gastrointest Endosc 2005;61:86-97.

15. Sahai AV, Mauldin PD, Marsi V, Hawes RH, Hoffman BJ. Bile duct stones and laparoscopic cholecystectomy: A decision analysis to assess the roles of intraoperative cholangiography, EUS, and ERCP. Gastrointest Endosc 1999;49:334-43.

16. Ainsworth AP, Rafaelsen SR, Wamberg PA, Durup J, Pless TK, Mortensen MB. Is there a difference in diagnostic accuracy and clinical impact between endoscopic ultrasonography and magnetic resonance cholangiopancreatography? Endoscopy 2003;35:1029-32.

17. Meenan J, Tibble J, Prasad P, Wilkinson M. The substitution of endocopic ultrasound for endoscopic retrograde cholangiopancreatography: Implications for service development and training. Eur J Gastroenterol Hepatol 2004;16:299-303.

18. Eisen GM, Dominitz JA, Faigel DO, et al, for the American Society for Gastrointestinal Endoscopy. Standards of Practice Committee. An annotated algorithm for the evaluation of choledocholithiasis. Gastrointest Endosc 2001;53:864-6.

19. Scheiman JM, Carlos RC, Barnett JL, et al. Can endoscopic ultrasound or magnetic resonance cholangiopancreatography replace ERCP in patients with suspected biliary disease? A prospective trial and cost analysis. Am J Gastroenterol 2001;96:2900-4.

20. Carlos RC, Scheiman JM, Hussain HK, Song JH, Francis IR, Fendrick AM. Making cost-effectiveness analyses clinically relevant: The effect of provider expertise and biliary disease prevalence on the economic comparison of alternative diagnostic strategies. Acad Radiol 2003;10:620-30.

21. Cohen S, Bacon BR, Berlin JA, et al. National Institutes of Health State-of-the-Science Conference Statement: ERCP for diagnosis and therapy. Gastrointest Endosc 2002;56:803-9.

22. Hilsden RJ, Romagnuolo J, May GR. Patterns of use of endoscopic retrograde cholangiopancreatography in a Canadian province. Can J Gastroenterol 2004;18:619-24. 


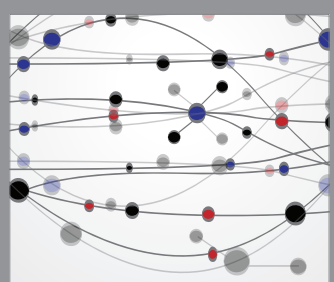

The Scientific World Journal
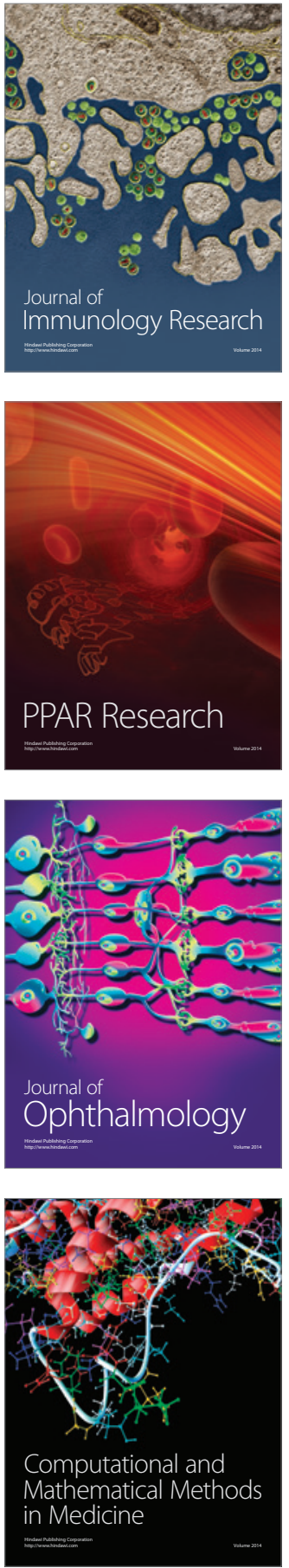

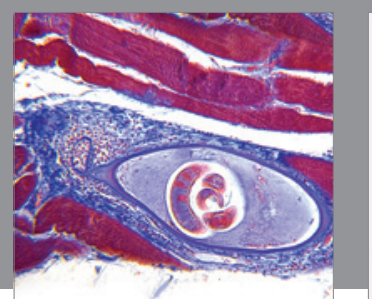

Gastroenterology Research and Practice

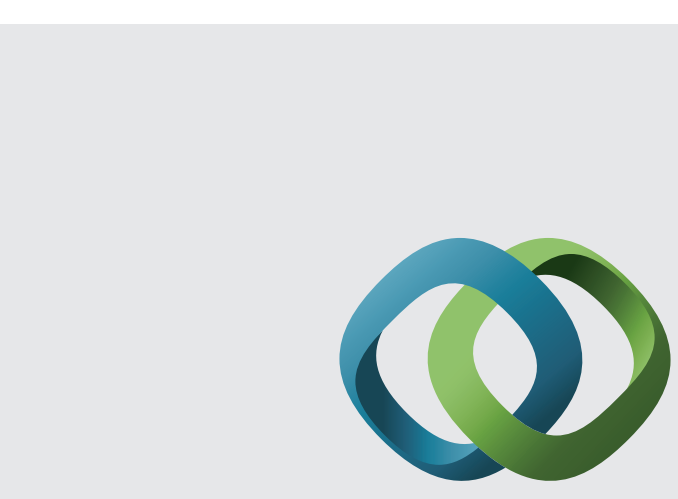

\section{Hindawi}

Submit your manuscripts at

http://www.hindawi.com
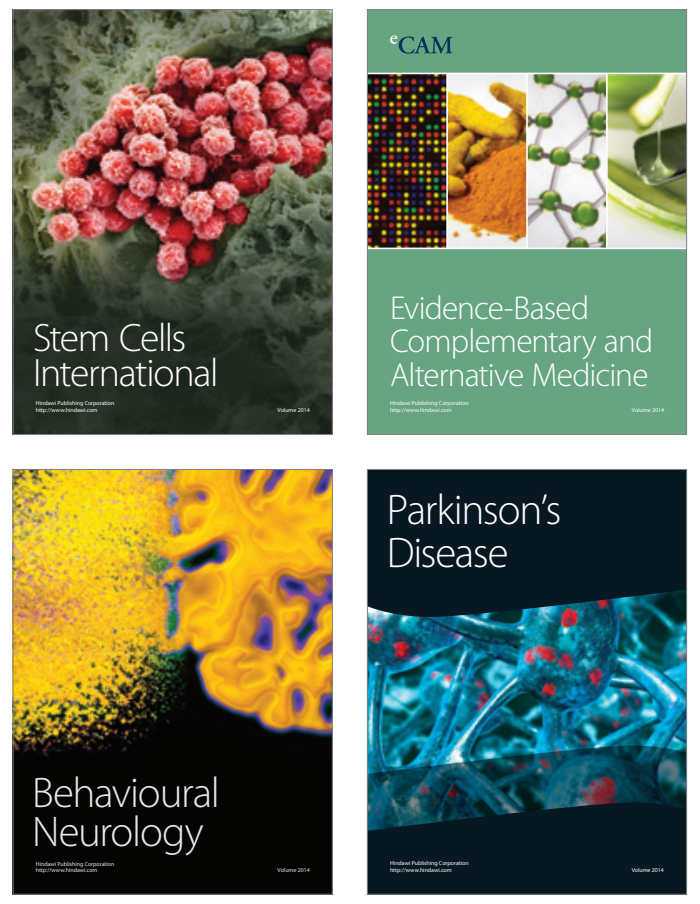
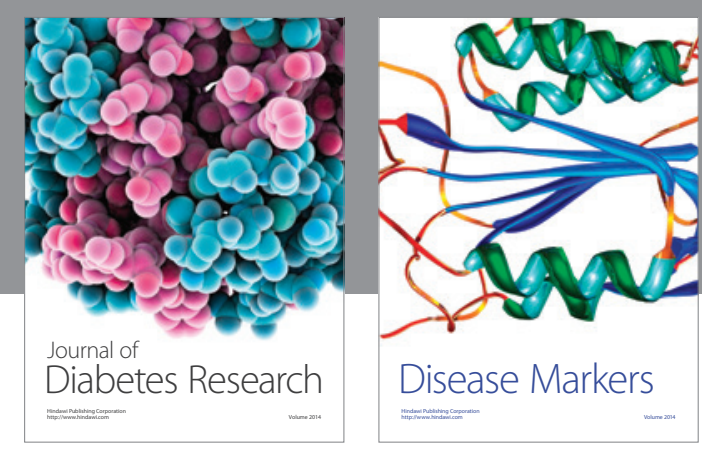

Disease Markers
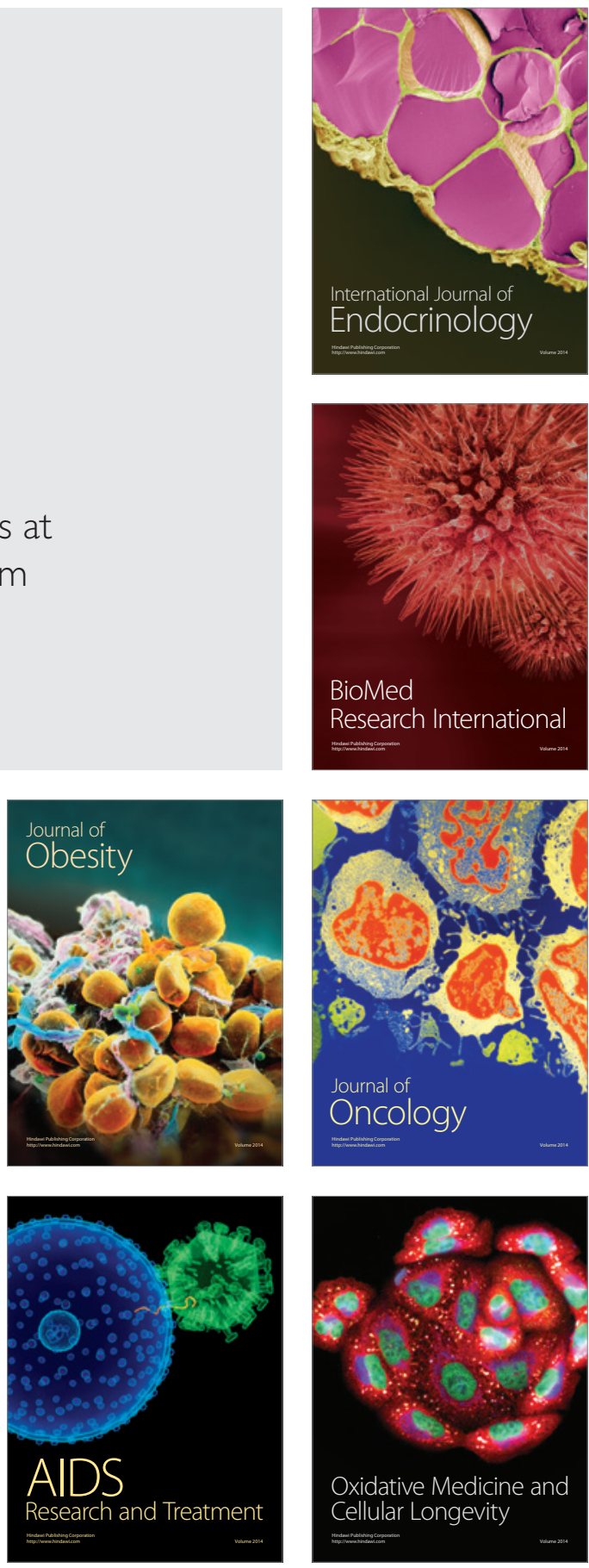